Alma Mater Studiorum - Università di Bologna DEPARTMENT OF ECONOMICS

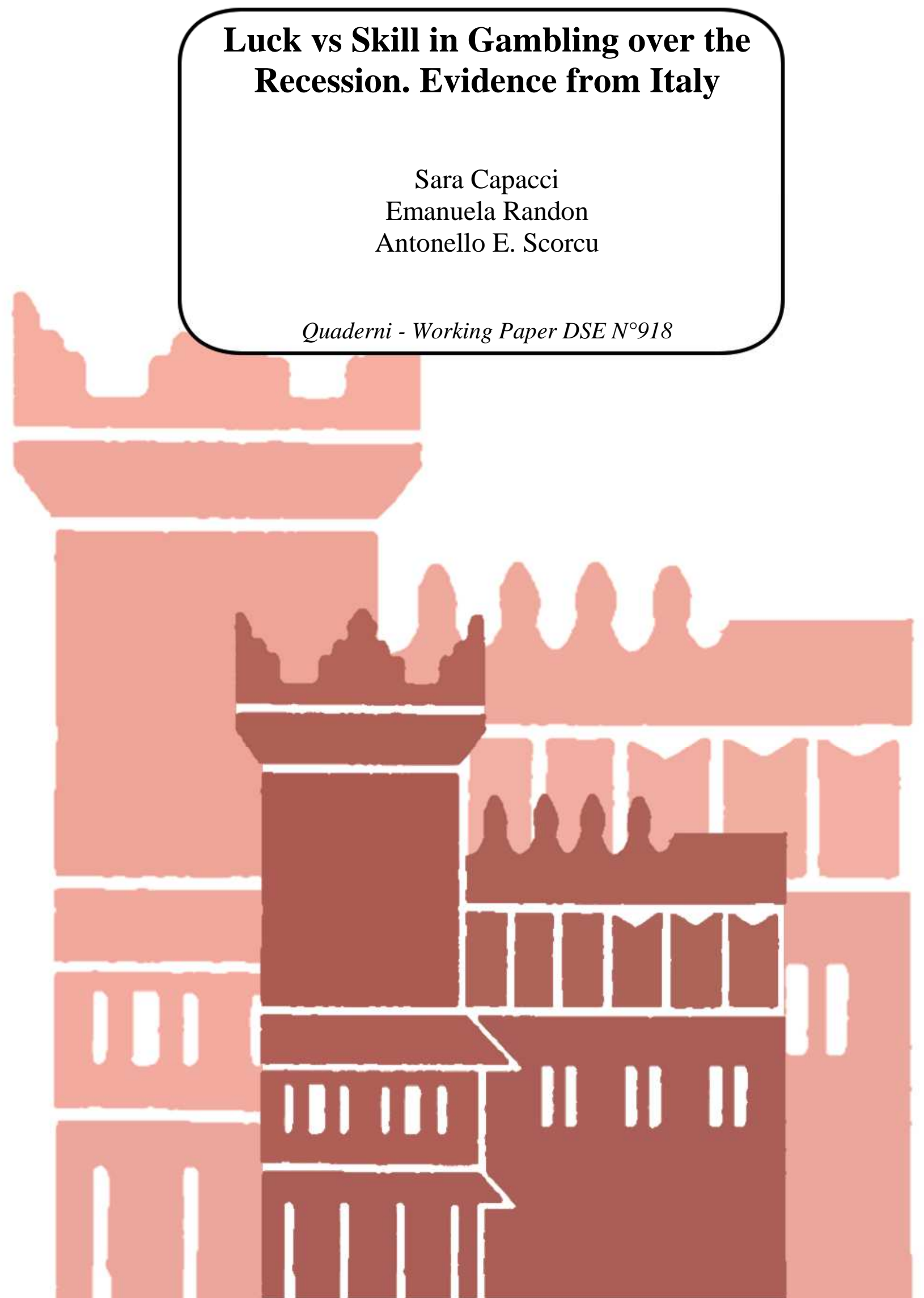




\title{
Luck vs Skill in Gambling over the Recession. Evidence from Italy
}

Sara Capacci ${ }^{\mathrm{a}}$

Emanuela Randon ${ }^{\mathrm{b}}$

Antonello E. Scorcu ${ }^{\mathrm{c}}$

\begin{abstract}
We perform an econometric analysis of the gambling market in Italy over the recession (20092012), observing the consumption patterns in "luck" and "skill" games. We find a different effect between the early and late period of the crisis. Whereas gambling initially behaves as normal good, in the long run luck games increase with the worsening of economic conditions. Moreover, skill games are more persistent and influence luck games, but not the opposite. Skill players choose simple lottery games, but luck players cannot handle complex games. Our results provide insights on investment choices in financial markets among expert and naïve buyers.
\end{abstract}

Keywords: Gambling, Economic Crises, Financial Investment

$J E L: \mathrm{D} 12, \mathrm{~L} 83, \mathrm{G} 01$

\footnotetext{
${ }^{a}$ Sara Capacci: Department of Economics, University of Bologna, Strada Maggiore 45, I-40126. Phone: +39 051209 2614. Email: sara.capacci@ unibo.it.

${ }^{\mathrm{b}}$ Emanuela Randon: Department of Economics, University of Bologna, Strada Maggiore 45, I-40126. Phone: +39051 209 2625. Email: emanuela.randon@unibo.it

${ }^{c}$ Antonello E. Scorcu: Department of Economics, University of Bologna, Strada Maggiore 45, I-40126. Phone: +39051 209 2611. Email: antonello.scorcu@ unibo.it
} 


\section{Introduction}

Within the large and growing literature on gambling, the analysis of the linkages between gambling expenditure and economic fluctuations is still limited. Several existing research works investigate the socio-economic and personal characteristics of the gamblers, often with the additional aim of testing alternative theories of choice under uncertainty (the Friedman and Savage expected utility models, the Kahneman and Tversky prospect theory, the utility of gambling (Conlisk (1993)). Therefore, most of the empirical research looks at the relevance of gambling for different groups of household (Kumar et al. (2011), Hayatbakhsh et al. (2006)) and at the motivations for individual participation in gambling markets ${ }^{1}$, finding a relatively high expenditure share for low income families (individuals) and an overall regressive effect (Tam (1991)).

In this paper, we analyse the macroeconomic dynamics of gambling expenditures in economic turndowns, focusing on whether people rely on fortune or ability when facing a recession. More precisely, we investigate the Italian gambling market through high-frequency (monthly) data and evaluate whether in such a period individuals tend to choose lottery-type activities that do not require any particular skill (luck games) or prefer games in which the development of specific capabilities and expertise can change the expected payoff of the "investor" (skill games).

The gambling sector has now a relevant impact on the GDP of countries. Although the financial crisis has decreased the extraordinary rate of growth experienced before the recession (24\% in 2004-2008), the industry at the global level is still expanding at a remarkable pace. In 2010, it accounted for 382 Billions with a growth rate of $8 \%$ and it is foreseen to reach $\$ 513$ Billion in $2015^{2}$, while Italian monthly expenditure in gambling activities reached 7 million euros in 2012 with a $58 \%$ increase since $2009^{3}$. The Italian case in this perspective is particularly interesting, as Italy has been hit heavily by the Great Recession, and from the fall 2007 it has been experiencing a strong drop in the GDP and an increase in unemployment rate. However, in the same period gaming expenditures grows significantly.

\footnotetext{
${ }^{1}$ These are related to different issues, such as the expected return or the effective price of the gambling (Clotfelter and Cook (1989), Gulley and Scott (1993), Scott and Gulley (1995), Walker (1998), Farrell and Walker (1999), Farrell at al. (1999), Forrest et al (2000), or the size of the jackpot as suggested by the prospect theory (Camerer (2000), DeBoer (1990), Shapira and Venezia (1992), Matheson (2001), Garrett and Sobel (2004)).

${ }^{2}$ Casinos \& Gaming: Global Industry Guide. Casinos \& Gaming: World Market Overview (Market size, Segmentation and Trends Analysis), Market Line Publication (2011), http://www.reportlinker.com/p0138969-summary/CasinosGaming-Global-Industry-Guide.html.

${ }^{3}$ Italian gambling regulatory authority (AAMS ) data, http://www.aams.gov.it
} 
It is thus interesting the analysis of the reasons and patterns of this lack of cyclical effect on the gambling expenditure in period of recession. Few empirical papers focus on this topic (Li et al. (2010)) and the empirical results are mixed. Using quarterly data of lottery state sales from 1983 to 1991, Mikesell (1994) finds that the positive and high real income elasticity is partially offset by the positive effect exerted by a rise of the unemployment rate. On the contrary, the analysis of specific game expenditures during the Asian financial crises 1997-1998 (Gu (1999), Raab and Schwer (2003)) suggests a serious decline in the propensity to spend in games. Over the period 1959-2010 the relationship between gambling expenditure and GDP dynamics in the US suggests that only lottery games are recession-proof (Horvath and Papp (2012)). Casino gambling and pari-mutuel wagering expenditure are instead affected by the economic conditions. However, there is no clear cut explanation of such a behaviour.

There are several different types of gambling and games, each characterized by specific expenditure levels, facility to play (on-line, at home, in casinos, hotels), and different learning strategies. Past works on gambling have focused on single types of games (Schettini Kearney, 2005; Perez and Humpreys, 2012) or on gambling "portfolio", with several, and possibly complex to model, substitution effects, due to technical innovations in the games and changes in the tastes of gamblers (Worthington, 2007; Levitzky et al., 2000). Our empirical strategy is instead to aggregate existing games into two classes, luck and skill games, that differ mainly because of the different perceived level of expertise and control of the outcome of the game by the consumer. In skill games (SG) the consumer can develop specific strategies of play and a "learning by doing" ability, even if the randomness remains crucial in determining the final outcome of the play. In luck games (LG), a rational individual recognizes that the outcome of the game is not influenced by the behaviour of the player and non specific expertise are required in playing such games.

As each class of games is composed by "similar" games, each of them displays a high degree of substitutability within the group. Moreover, aggregate expenditure over the two classes of games are likely to be correlated, since a change in a common determinant - like a change in the overall economic condition - is expected to affect the expenditure allocation between them. For such a reason, we start estimating a simultaneous equation model, using high frequency aggregate data (monthly data) from 2009 to late $2012^{4}$. However, exclusion tests on the coefficients neatly induce to reject the hypothesis of contemporaneous interdependence among skill and luck.

No simultaneous effect emerges, but a causal relationship between them (i.e. the lagged value of skill games influences the luck games, but not the opposite). Skill players may choose simple

\footnotetext{
${ }^{4}$ The release of official data on games expenditures unexpectedly ended in early 2013 without any clear explanation.
} 
lottery games, but the luck players do not have the expertise for complex games. These findings can be extended to financial markets, in order to investigate if in period of hardships people prefer complex financial products (i.e. financial spread betting or CFD) or simple lottery-type investments characterized by low prices, high volatility of returns and a positive skewness.

Moreover, our results show that LG expenditure does not depend on their own lagged values but is influenced by the current economic conditions. On the contrary, SG expenditure tends to be more persistent over time, but less dependent on the economic conditions, as they provide an alternative (but much more risky) source of income.

Differences in patterns between the early phase and the crises and the long-run are also investigated. According to our econometric estimates at the beginning of the recession, gambling behaves as a normal good. The expenditures react positively to an increase in the household "sentiment" and negatively to the increase in unemployment. In the late period of the crisis, however, luck gaming expenditure becomes an inferior good, increasing with the worsening of the climate and unemployment rate.

The paper is structure as follows. In sections 2 and 3 we describe our modeling strategy and the data set; in section 4 we discuss the empirical evidence. Some final remarks conclude the paper.

\section{Modelling Strategy}

A gambler can choose among a wide type of games, with different characteristics - the mechanism of the game, the price, the payoff, the facility to play (on-line, at home, in casinos, hotels). The demand of each game reacts differently to all these features. We assume that the overall amount of money devoted to gambling ${ }^{5}$ is allocated between two classes of games, i.e. luck and skill games, on the basis of the individual preferences and the characteristics of each class of games (e.g. its prize structure), similarly to a financial asset allocation process. As a change in the characteristics or the composition of one class might affect the income share allocated to the other class ${ }^{6}$ and common explanatory variables or unobservable shocks might simultaneously influence expenditures on the two types of games, the skill and luck expenditures series are likely to be correlated. Thus, our modeling strategy allows for the existence of simultaneous effects.

Our initial specification for the gross total expenditure on games $(\mathrm{G})$ is:

\footnotetext{
${ }^{5}$ Obviously, this amount of money might be pathologically high.

${ }^{6}$ The degree of substitutability among "similar" games within a group is high: instantaneous lotteries have crowded out the traditional ones; on-line bets on specific football matches have crowded out the traditional weekly bet on the whole football tournament. These reshuffling in luck or skill games, however, are not considered.
} 
$G_{t}=f\left[X_{t-i}, G_{t-i-1}\right]+u_{t}$

whereas the initial model for the skill and luck expenditure is:

$$
\begin{array}{lr}
S G_{t}=f_{S}\left[X_{t-i}, X_{t-i}^{S G}, S G_{t-i-1}, L G_{t-i}\right]+u_{t}^{S G} & \mathrm{i}=0,1, \ldots \\
L G_{t}=f_{L}\left[X_{t-i}, X_{t-i}^{L G}, L G_{t-i-1}, S G_{t-i}\right]+u_{t}^{L G} & \mathrm{i}=0,1, \ldots
\end{array}
$$

where $t=0,1, .$. is the time index; $i=0,1, .$. is the lag index; $(\mathrm{X})$ is a set of common explanatory variables describing the overall economic conditions (the total and male unemployment rates, the industrial production index and a set of household confidence indices); $\left(\mathrm{X}^{\mathrm{LG}}\right)$ and $\left(\mathrm{X}^{\mathrm{SG}}\right)$ are two vectors of explanatory variables specific to the LG and SG regressions, respectively. Since only a relatively low number of series are available at the monthly frequency, and none of them could be considered specific for one class of gambling, all idiosyncratic influences on luck and skill expenditures are summarized by the constant terms of the estimated model. $\left(\mathrm{u}^{\mathrm{LG}}\right)$ and $\left(\mathrm{u}^{\mathrm{SG}}\right)$ are two zero mean, constant variance error terms of the $\mathrm{LG}$ e $\mathrm{SG}$ regressions with $\operatorname{cov}\left(\mathrm{u}^{\mathrm{LG}}, \mathrm{u}^{\mathrm{SG}}\right) \neq 0$.

The model is completed with a binary indicator of the regime shift (RS) in the perception of the crisis, used as interaction term with other variables. According to the empirical evidence shown in the following section, the shift is assumed to be effective from June 2011.

A general two equation simultaneous system and two Seemingly Unrelated Regressions have been estimated in order to test for the existence of any structural simultaneous link or common shock between the two series. Neither of the two receive empirical support, and in the following we will show only the final OLS specifications.

\section{Data description}

The empirical investigation is based on official Italian data about monthly gambling expenditure (January 2009 - October 2012), as provided by the Italian gambling regulatory authority ${ }^{7}$. Eight different game types are aggregated into the two main classes of luck and skill games, according to the different role of ability and fortune in determining the outcome, as described in the previous section. The skill category includes horse racing and sport related pari-mutuel betting and online skill games (cards and non-cards games). The luck category groups the remaining games, like traditional, instant and video lotteries, slot machines, etc. (see Table 1 for disaggregated monthly averages). The analysis is thus performed on the three series of aggregate expenditure: gross total, skill and luck gambling expenditure, at current prices.

Total gambling expenditure has experienced an impressive growth in the last few years. At the

${ }^{7}$ AAMS, Amministrazione Autonoma dei Monopoli di Stato. http://www.aams.gov.it. 
beginning of the period under scrutiny (2009) expenditure was 54 BN€ and reached 77 BN€ in 2011, with a 44\% increase in a two-years span. Moreover, also the composition of gambling expenditure has changed over time.

Figure 1 - Gross expenditure in luck games and skill games (logarithm, January 2009October 2012)

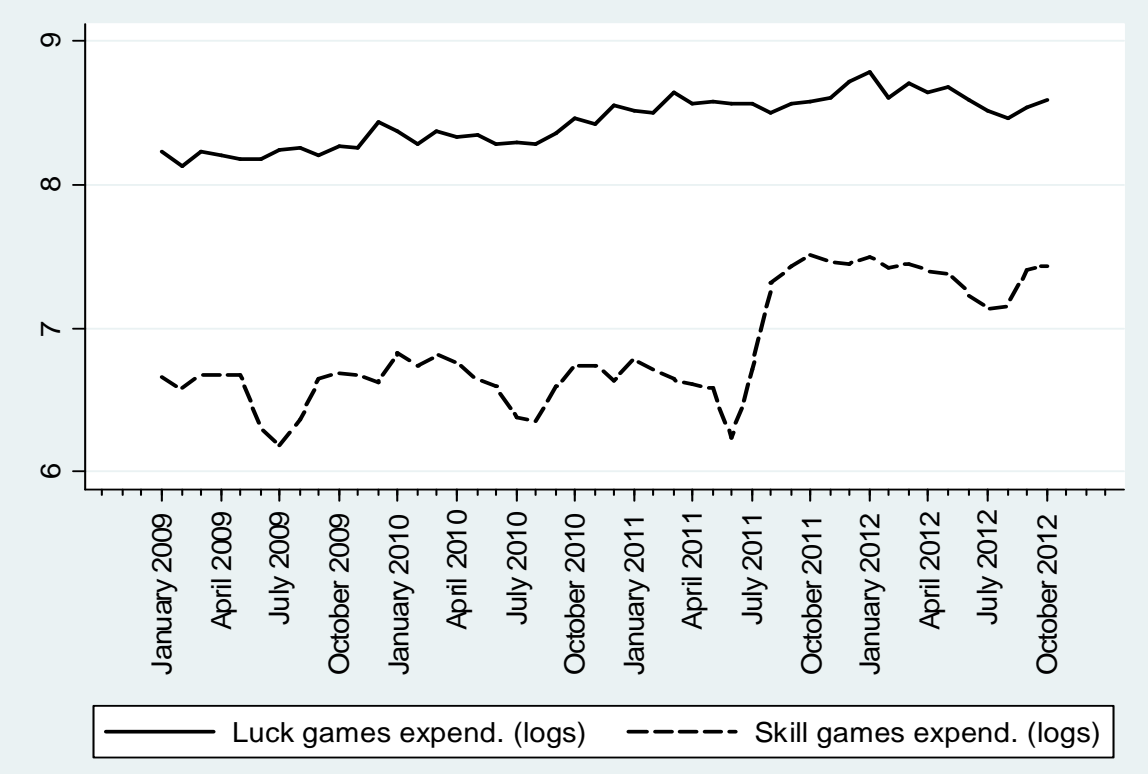

In Figure 1 the logarithm of luck and skill expenditures are plotted against time. Throughout the four-year period the skill games series shows seasonal drops during summer months, and a strong increase after July 2011 when cash games as the online poker have been liberalized. On the contrary, any seasonal pattern is apparent on the luck series, whilst a feeble "Christmas peak" can be detected ${ }^{8}$.

As shown in Table 1, average monthly investments in both ability and fortune games have increased every year since 2009. The share of skill game expenditure has started increasing in 2011, moving from about $15 \%$ of total gambling expenditure to $22 \%$ in 2012 . The liberalization of online cash games which occurred in July 2011 has contributed to that transition, widening the portfolio of Italian gamblers.

The potential explanatory variables consist of a limited number of monthly time series. We consider four indices of household confidence (about economic, personal situation, overall current and future situations) to capture the attitude and expectation over the business climate and the level of optimism/pessimism, the seasonally adjusted industrial production index and the overall and male

\footnotetext{
${ }^{8}$ The traditional National Lottery (Lotteria Italia) drawings are held every year on $6^{\text {th }}$ January and tickets sales reach the peak during Christmas holidays.
} 
unemployment rates ${ }^{9}$. Whereas the monthly frequency reduces the number of series available for the current empirical investigation, nevertheless it allows a neat understanding of the dynamic linkages between the two classes of games.

Table 1 - Average monthly gambling expenditure (M€) by game type and year (2009-2012)

\begin{tabular}{|c|c|c|c|c|c|c|c|c|}
\hline & \multicolumn{2}{|c|}{2009} & \multicolumn{2}{|c|}{2010} & \multicolumn{2}{|c|}{2011} & \multicolumn{2}{|c|}{$2012^{\mathrm{a}}$} \\
\hline & Mean & St.Dev. & Mean & St.Dev. & Mean & St.Dev. & Mean & St.Dev. \\
\hline Slot machines & 2079.27 & 203.59 & 2627.83 & 283.93 & 3537.58 & 332.90 & 3881.54 & 415.31 \\
\hline Bingo & 121.21 & 19.43 & 162.17 & 12.62 & 154.17 & 10.15 & 137.78 & 15.19 \\
\hline Traditional Lotteries & 786.28 & 96.93 & 778.92 & 68.02 & 845.92 & 70.04 & 816.80 & 82.30 \\
\hline Lotto & 471.96 & 32.57 & 435.92 & 55.03 & 567.50 & 42.74 & 513.35 & 35.33 \\
\hline $\begin{array}{l}\text { Parimutuel numerical } \\
\text { games }\end{array}$ & 314.68 & 140.95 & 293.58 & 70.10 & 199.67 & 19.50 & 150.77 & 24.14 \\
\hline Luck games & 3773.39 & 301.11 & 4298.42 & 371.21 & 5304.83 & 335.22 & 5500.24 & 538.17 \\
\hline Horse-race betting & 164.78 & 19.78 & 144.08 & 15.20 & 114.08 & 17.07 & 82.48 & 6.73 \\
\hline Sport event betting & 347.27 & 94.24 & 374.75 & 86.69 & 327.00 & 100.06 & 319.99 & 81.90 \\
\hline Online skill games & 195.64 & 35.46 & 262.08 & 22.01 & 701.50 & 505.23 & 1162.00 & 121.66 \\
\hline Skill games & 707.69 & 110.67 & 780.92 & 113.82 & 1142.58 & 498.31 & 1564.47 & 189.05 \\
\hline Gross gambling exp. & 4481.1 & 329.3 & 5079.3 & 422.8 & 6447.4 & 673.6 & 7023.5 & 660.2 \\
\hline$\%$ Skill games exp. & $15.8 \%$ & & $15.4 \%$ & & $17.7 \%$ & & $22.3 \%$ & \\
\hline$\%$ Luck games exp. & $84.2 \%$ & & $84.6 \%$ & & $82.3 \%$ & & $78.3 \%$ & \\
\hline
\end{tabular}

Source: Italian government (AAMS)

${ }^{\text {a }}$ The monthly average is computed over 10 months (January-October), according to the available data

Plots of the four household confidence indices are shown in Figure 2. The economic and the general future climate indices drop at the beginning of 2009 and of 2010 and then show a stable pattern until mid- 2011.

\footnotetext{
${ }^{9}$ All the series are provided by the Italian National Institute of Statistic.
} 
Figure 2 - Indices of Household Confidence (current, future, economic and personal climate)

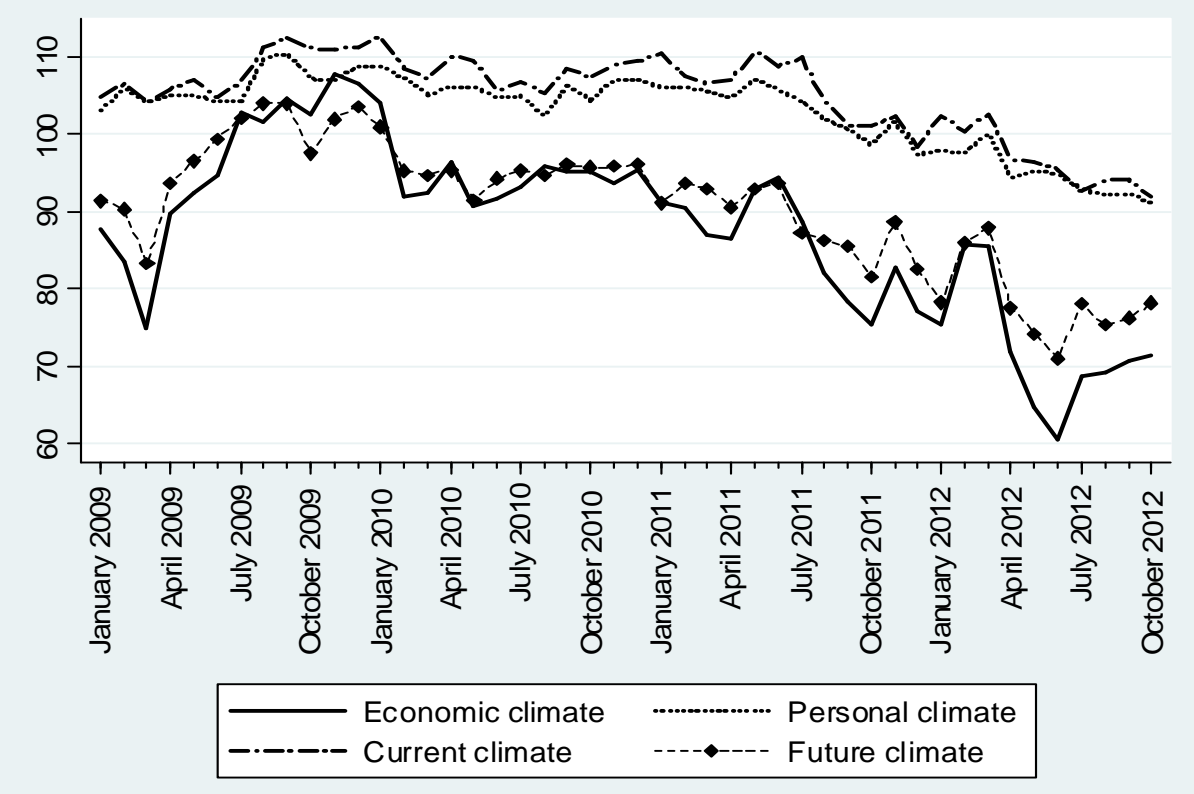

In the same period the personal and the current climate series, which have only slightly fluctuated since the beginning of the period under scrutiny, start displaying a decreasing pattern. All the series decisively drop during the spring and summer months in 2011, as if households at that moment have started perceiving the economic recession as a personal threat rather than a generic negative economic circumstance of the country as a whole. According to these patterns (particularly the future climate indicator) only in mid-2011 households become fully aware of the crises.

Figure 3 - Total Unemployment rate (\%) and Industrial Production Index

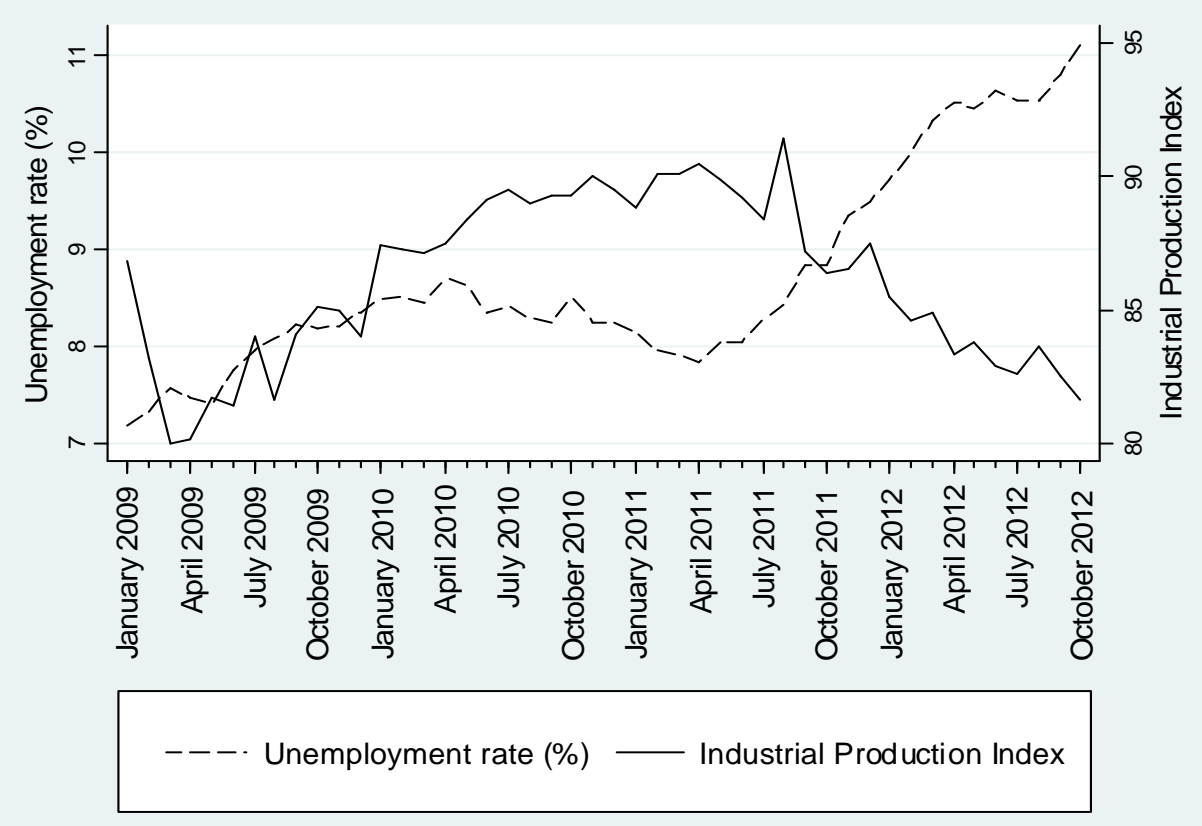


A neat deterioration of some key structural indicators (see Figure 3) like the national unemployment rate (dramatically increasing since April 2011) or the industrial production index (with an opposite pattern) contribute to this general worsening in expectations.

As it will be discussed in the following sections, these changes evidence a transition from a temporary shock to a permanent one. For this purpose a binary indicator for a regime shift will be introduced in the model, taking the value 1 from June 2011 on.

\section{Empirical evidence}

The results of the regression for the overall monthly expenditure on gambling are shown in Table 2, Column 1. Total games spending shows a sizeable degree of persistence (a one percent increase in game expenditure in the past month translates into a $0.48 \%$ in the current month). As expected, the liberalization of cash games (particularly on-line poker) occurred in mid-2011 has a deep impact on gambling habits, determining a significant increase in the average amount spent every month (as shown by the positive coefficient of the poker dummy). The prompt reaction to liberalization observed in expenditure levels, however, might suggest also switch from previously illegal to legal activities. Moreover a significant direct relation with the consumer confidence index and a weak positive time trend complete the picture. The explanatory power of the regression is high and the specification used shows no sign of misspecification, omitted variables or autocorrelation in the residuals.

Yet, the distinguishing feature of our analysis is the disaggregation of the gross overall expenditure into skill and luck games expenditures. We start by estimating a general (and possibly overparametrized) two equations simultaneous system. However, a series of exclusion tests lead us to reject the hypothesis of any structural simultaneous link between the two series. In the second step of our modelling strategy two Seemingly Unrelated Regressions have been estimated, as skill and luck expenditures might be linked through a common shock. Again, the size of the estimated correlation coefficient between the residuals of the two regressions (0.078) and the Breusch-Pagan test about their independence (0.602 P-value) exclude any correlation among the series of the residuals. In fact, the SUR coefficients (not reported for the sake of brevity) are analogous in sign, size and significance to the OLS estimates, shown in Table 2, columns 2 and $3^{10}$. Diagnostic tests for both OLS equations show a high explanatory power and the lack of serial correlation, as the Breusch - Godfrey and the Durbin-h tests do not reject the null. The Breusch - Pagan test for heteroskedasticity displays no sign of misspecification for the LG regression, but not for the SG

\footnotetext{
${ }^{10}$ The 3SLS and SUR estimates, as well the relevant specification tests, are available upon request from the authors
} 
regression. The reported heteroskedasticity consistent standard errors (White procedure), however, support the reliability of the estimated coefficients ${ }^{11}$.

With regard to time persistency, SG is influenced by its one month lagged value, revealing that consumption of ability-intense games are usually the outcome of a long lasting learning process. No persistency emerges in LG.

The lack of contemporaneous interdependency between the expenditure on the two types of games (neither in terms of structural effects nor among the SUR residuals), does not prevents the emergence of dynamics effects. The empirical evidence suggests that luck games expenditure is influenced by previous levels in skill games spending (Column 3), revealing skilled investors probably diversify their games portfolio choosing both types of games, while the contrary does not occur. A one percent increase in the lagged SG raises the current LG by $0.17 \%$, while a positive time trend influences uniquely the average spending in fortune-games.

Besides, as expected, the coefficient of the dummy for the introduction of distance cash-games (poker dummy) is highly significant for the SG equation only, as the liberalization concerned a set of ability games exclusively.

Table 2 - Gross expenditure on Total, Skill and Luck Game (OLS Estimation, no Regime Shift)

\begin{tabular}{lccc}
\hline & (1) Log Gross total Exp. & (2) Log Gross Skill Exp. & (3) Log Gross Luck Exp. \\
\hline N. obs & 45 & 45 & 45 \\
$\mathrm{R}^{2}$ & 0.917 & 0.906 & 0.881 \\
Adj $\mathrm{R}^{2}$ & 0.909 & 0.899 & 0.869 \\
$\mathrm{~F}$ test & $\mathrm{F}(4.40)=110.51[0.000]$ & $\mathrm{F}(3.41)=131.77[0.000]$ & $\mathrm{F}(4.40)=73.65[0.000]$ \\
Root MSE & 0.061 & 0.127 & 0.063 \\
Breusch-Godfrey test $\left(\mathrm{Chi}^{2}\right)$ & $0.337[0.561]$ & $2.079[0.149]$ & $0.345[0.557]$ \\
Durbin test $\left(\mathrm{Chi}^{2}\right)$ & $0.295[0.587]$ & $1.938[0.164]$ & $0.302[0.583]$ \\
Breusch-Pagan test $\left(\mathrm{Chi}^{2}\right)$ & $0.020[0.896]$ & $5.860[0.016]$ & $0.100[0.748]$ \\
\hline & & & $1.199[0.489]$ \\
Constant & $-0.643[0.673]$ & $-5.647[0.085]$ & - \\
Log Games Exp $(-1)$ & $0.484[0.000]$ & - & $0.166[0.000]$ \\
Log Skill Exp $(-1)$ & - & $0.415[0.000]$ & - \\
Poker dummy & $0.135[0.009]$ & $0.672[0.000]$ & $1.317[0.000]$ \\
Log Current confidence & $1.054[0.004]$ & $2.029[0.004]$ & $-0.050[0.021]$ \\
Male unemployment rate & - & - & $0.016[0.000]$ \\
Trend & $0.006[0.001]$ & - & \\
\hline
\end{tabular}

\footnotetext{
${ }^{11}$ The results, not shown for the sake of brevity, are available on request.
} 
We then investigate the change of regime from temporary downturn to persistent shock. If we do not consider any regime shift, a one percent increase in the household sentiment about the current overall situation is always magnified in terms of game expenditure: it raises SG and LG by $2 \%$ and $1.32 \%$, respectively (see Table 2). LG is also negatively influenced by the male unemployment rate. Both fortune-intense and ability-intense games seem to be demanded as normal goods. However, it is important to incorporate in the analysis the perception of the regime shift. The severity of the crises was initially underestimated in most European countries. As the shocks were transmitted throughout the world and from financial to real markets, fiscal policies often failed to react promptly, and households draw heavily on accumulated saving to offset what was perceived as a strong but still temporary shock. Italian households seem to become fully aware of the severity of the crisis only in mid-2011, when the crises of the sovereign debt and the sharp increase in the yield of the Italian bonds lead to a government collapse and change, and to a rise in taxes and a drastic cut in public expenditures (as confirmed by Figure 2 and 3 in Section 2).

We model such a change in people perception by multiplying the previous variables with a regime shift dummy which is equal to zero up to May 2011 and to one thereafter, as the regime shift exerts its effect through the evaluation of the overall economic situation.

Tables 3 summarizes the estimates of the total, skill and luck regressions after including the regime shift. Whereas no clear regime shift effect can be detected for G (no RS-interaction term results statistically significant, Table 3, Column 1), the patterns of SG and LG change according to the perceived length and severity of the crisis (Columns 2 and 3).

With regard to the skill regression, the lagged expenditure in skill games positively affects the current expenditure both in the first phase of the crises and in the last period, although its effect becomes weaker after the regime shift. Similarly, the overall effect of households' confidence on the SG expenditures remains positive over the whole period, while the change in the perception of the crisis has only slightly shrunk its magnitude.

LG reacts differently to the change in regime. The lagged SG coefficient does not change with the regime shift, while the current confidence effect becomes weaker. More importantly, the regime shift reverses the sign of the trend variable and of the male unemployment rate, negative at first (0.089 , as expected for normal goods), but positive in the last period (0.217), suggesting that when the crisis is perceived as persistent, LG starts behaving as "bad" goods, whose demand increases with the worsening of the economic conditions.

Note that, since the change in the regime, measured by the household confidence indices, occurred almost at the same period of the liberalization of the cash games, a problem of identification arises. In fact, the poker dummy exerts no significant effect on the luck games expenditure, as there is no simultaneous link between the two classes of spending, and the only indirect link is the one month 
lagged effect of the skilled expenditure. Since the household confidence and the male unemployment rate interacted with the RS dummy both exert a significant effect on SG and LG, we are inclined to associate the changes in the slopes to the regime shift for the luck games expenditure and, at least partially, for the skill games expenditure.

Table 3 - Gross expenditure on Total, Skill and Luck Games (OLS Estimation with Regime Shift)

\begin{tabular}{|c|c|c|c|}
\hline & (1) Log Gross total Exp. & (2) Log Gross Skill Exp. & (3) Log Gross Luck Exp. \\
\hline N. obs & 45 & 45 & 45 \\
\hline $\mathrm{R}^{2}$ & $\mathrm{~F}(6,38) 71.12[0.000]$ & $\mathrm{F}(7,37)=83.82[0.000]$ & $F(7,37)=54.50[0.000]$ \\
\hline Adj $R^{2}$ & 0.918 & 0.941 & 0.912 \\
\hline F test & 0.905 & 0.930 & 0.895 \\
\hline Root MSE & 0.061 & 0.106 & 0.056 \\
\hline Breusch-Godfrey test $\left(\mathrm{Chi}^{2}\right)$ & $0.369[0.544]$ & $3.599[0.058]$ & $0.171[0.679]$ \\
\hline Durbin test $\left(\mathrm{Chi}^{2}\right)$ & $0.306[0.580]$ & $3.129[0.077]$ & $0.137[0.711]$ \\
\hline Breusch-Pagan test $\left(\mathrm{Chi}^{2}\right)$ & $0.010[0.908]$ & $3.220[0.073]$ & $0.100[0.757]$ \\
\hline Constant & $-0.724[0.646]$ & $-9.611[0.019]$ & $2.234[0.304]$ \\
\hline Log Games Exp. (-1) & $0.489[0.000]$ & - & - \\
\hline Log Games Exp. RS (-1) & $0.006[0.531]$ & - & - \\
\hline Log Skill Exp. (-1) & - & $0.634[0.000]$ & $0.084[0.070]$ \\
\hline Log Skill Exp. RS (-1) & - & $-0.336[0.067]$ & - \\
\hline Poker dummy & $0.120[0.140]$ & $0.563[0.006]$ & - \\
\hline Log Current confidence & $1.062[0.005]$ & $2.568[0.003]$ & $1.267[0.008]$ \\
\hline Log Current confidence RS & $-0.010[0.476]$ & $-0.160[0.017]$ & $-0.134[0.052]$ \\
\hline Log Current confidence RS (-1) & & $0.587[0.021]$ & \\
\hline Male unemployment rate & & & $-0.089[0.011]$ \\
\hline Male unemployment rate RS & & & $0.306[0.001]$ \\
\hline Trend & $0.007[0.002]$ & & $0.017[0.000]$ \\
\hline Trend RS & & $0.013[0.175]$ & $-0.053[0.002]$ \\
\hline
\end{tabular}

In conclusion, if we incorporate a different perception of the severity of the crisis, game expenditures behave as normal goods in the early period, whereas in the long run luck game expenditure behaves oppositely, increasing while economic circumstances deteriorate. This suggests that naive buyers perceive gambling as an alternative source of income in economic turndowns.

\section{Conclusion}

In this paper, we develop an empirical analysis of the gambling market in Italy over the Great 
recession (2009-2012) in order to investigate if people prefer activities based on ability or fortune in period of economic hardship. For this purpose, the behavior of luck and skill gamblers are analyzed, using high frequency aggregate data. According to our estimates no significant simultaneity exists. Indeed, we show that "skill" expenditure influences "luck" expenditure (through the skill lagged variables), while the inverse relationship is not verified. This can give some insights to financial markets, where "naïve" buyers invest only in simple-lottery product, while "skilled" investors choose for portfolio diversification. Overall, we find that expenditures on ability games are more persistent and less influenced by macroeconomic fluctuations than expenditures on fortune games. This might be clearly related to the learning commitment required for ability-intense games, which makes demand changing more rigidly.

Interestingly, we find a different behavior of players along the cycle of the recession. In the first phase, gambling products are perceived as normal goods, reacting positively to the climate or sentiment of the consumer and negatively to the unemployment rate. On the contrary and differently from ability games, in the last phase expenditures in luck games increase with the worsening of the economic conditions (the coefficient of the unemployment turns positive). Assuming people start being completely aware of the severity of the economic crisis around mid-2011 (as the dramatic drop in households confidence indices suggests) we can conclude luck games are demanded as inferior goods during economic downturn, increasingly perceived as a source of secondary income by naïve investors. Finally, these results certainly recall differential patterns of investment choices in financial markets between expert and naïve buyers. The latter focusing on simple lottery-type investments with low prices, high volatility of returns and a positive skewness, while the former performing portfolio diversification and choosing more complex financial products (i.e. financial spread betting or CFD). This paper suggests that the linkages between gambling and financial markets can be further developed in future works.

\section{References}

-Barberis, N., Huang, M., 2008. Stocks as lotteries: the implications of probability weighting for security prices. American Economic Review, 98, 2066-100.

-Camerer, C. 2000. Prospect theory in the wild: evidence from the field. In: Kahneman, D., Tversky, A., (Eds). Choices, Values and Frames. Cambridge: Cambridge University Press, 288300.

-Casinos \& Gaming: Global Industry Guide. World Market Overview (Market size, Segmentation and Trends Analysis), Market Line Publication (2011), http://www.reportlinker.com/p0138969summary/Casinos-Gaming-Global-Industry-Guide.html. 
-Clotfelter, C., Cook, P., 1989. Selling Hope: State Lotteries in America. Cambridge: Harvard University Press.

- Conlisk, J., 1993. The utility of gambling. Journal of Risk and Uncertainty 6: 255-275.

-DeBoer, L., 1990. Lotto sales stagnation: Product maturity or small jackpots?. Growth and Change 21, 73-7.

-Farrell, L., Walker, I., 1999. The welfare effects of lotto: Evidence from the UK. Journal of Public Economics 72, 99-120.

-Farrell, L., Morgenroth, E., Walker, I., 1999. A time series analysis of U.K. lottery sales: Long and short run price elasticities. Oxford Bulletin of Economics and Statistics 61, 513-26.

-Forrest, D., Gulley, O.D., Simmons, R., 2000. Elasticity of demand for UK National Lottery tickets. National Tax Journal 53, 853-64.

-Forrest, D., R. Simmons and N. Chesters. Buying a dream: Alternative models of demand for lotto. Economic Inquiry 40, 2002, 485-496

-Forrest, D., O. Gulley and R. Simmons. The relationship between betting and lottery play. Economic Inquiry 48, 2010, 26-38

-Garrett, A.T., Sobel, R.S., 1999. Gamblers favor skewness, not risk: Further evidence from United States' lottery games. Economics Letters 63, 85-90.

-Garrett, T.A., Sobel, R., 2004. State lottery revenue: The importance of game characteristics. International Review of Applied Economics 15, 213-27.

-Gulley, O., Scott, F., 1993. The demand for wagering on state-operated lotto games. National Tax Journal 46, 13-22.

-Gu, Z., 1999. The Impact of the Asian financial crisis on Asian gaming activities: An examination of Las Vegas strip casino drops. Current Issues in Tourism 2, 354-65.

-Hayatbakhsh, M.R., Najman, J.M., Aird, R., Bor, W., O’Callaghan, M., Williams, G., Shuttlewood, G., Alati, R., Heron, M., 2006. Early Life Course Determinants of Young Adults' Gambling Behaviour. An Australian Longitudinal Study. Office of Gaming Regulation: Queensland Treasury.

-Horvath, C., Paap, R., 2012. The Effect of Recessions on Gambling Expenditures. Journal of Gambling Studies 28, 703-17.

-Kumar, A., 2009. Who gambles in the stock market?. Journal of Finance 13, 1889-1933.

-Kumar, A., Page, J.K., Spalt, O.G., 2011. Religious beliefs, gambling attitudes, and financial market outcomes. Journal of Financial Economics 102, 671-708.

-Levitzky, I., Assane, D., Robinson, W., 2000. Determinants of gaming revenue: extent of changing attitudes in the gaming industry. Applied Economics Letters 7, 155-58. 
-Li, G., Gu, X., Siu, R.C.S., 2010. The impacts of gaming expansion on economic growth: A theoretical reconsideration. Journal of Gambling Studies 26, 269-85.

-Matheson, V., 2001. When are state lotteries a good bet?. Eastern Economic Journal 27, 13-22.

-Mikesell, J.L., 1989. A Note on the Changing Incidence Of State Lottery Finance. Social Science Quarterly 70, 513-21.

-Mizerski, D., Miller, R., Mizerski, C., Lam, D., 2004. The Stochastic Nature of Purchasing a State's Lottery Products. Australasian Marketing Journal 12, 56-69.

-Perez, L. and B. Humphreys. The "who and why" of lottery: Empirical highlights from the seminal economic literature. Journal of Economic Surveys 27, 2013, 915-940.

-Raab, C., Schwer, R., K., 2003. The short- and long-term impact of the Asian financial crisis on Las Vegas Strip baccarat revenues. Hospitality Management 22, 37-45.

-Schettini, K. M., 2005. State lotteries and consumer behaviour. Journal of Public Economics 89, 2269-99.

-Scott, F., Gulley, O., 1995. Testing for efficiency in lotto markets. Economic Inquiry 33, 175-88.

-Shapira, Z., Venezia, I., 1992. Size and frequency of prices as determinants of the demand for lotteries. Organizational Behaviour and Human Decision Processes 52, 307-18.

-Tam, M.S., 1991. Tax on price: a new commodity tax structure for efficiency. Public Finance 46, 123-33.

-Walker, I., 1998. The economic analysis of lotteries. Economic Policy 13, 359-92.

-Worthington, A.C., Brown, K., Crawford, M., Pickernell, D. (2007), Gambling Participation in Australia: Findings from the National Household Expenditure Survey. Review of the Economics of the Household 5, 209-21. 


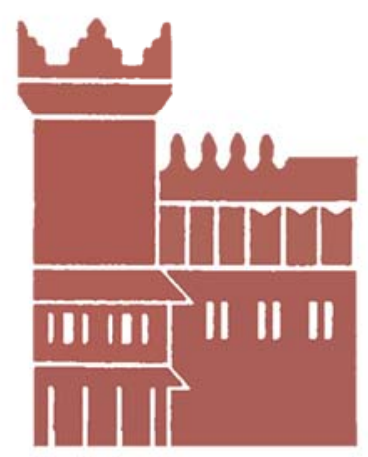

Alma Mater Studiorum - Università di Bologna DEPARTMENT OF ECONOMICS

Strada Maggiore 45

40125 Bologna - Italy

Tel. +39051 2092604

Fax +390512092664

http://www.dse.unibo.it 